\title{
Abnormal tongue features as a clinical clue for late-onset Pompe's disease
}

Achado anormal na língua como dica clínica para doença de Pompe de início tardio

Wladimir Bocca Vieira de Rezende Pinto ${ }^{1}$, Paulo Victor Sgobbi de Souza', Thiago Bortholin', Fernando George Monteiro Naylor', Acary Souza Bulle Oliveira ${ }^{1}$

A 58-year-old woman presented with slowly-progressive lower limb weakness. Medical history disclosed a six-year history of obstructive sleep apnea syndrome (OSAS). Examination disclosed abnormal tongue features (Figure 1) and proximal flaccid tetraparesis. Muscle MRI showed marked compromise of the adductor magnus, and muscle biopsy disclosed vacuolar myopathy with PAS-positive vacuoles (Figure 2). Dried blood spot-based GAA (acid alpha-glucosidase) activity testing and $G A A$ gene sequencing confirmed late-onset Pompes disease (LOPD). Clinicians should consider LOPD in cases of limb-girdle weakness with atypical findings ${ }^{1}$, such as obstructive sleep apnea syndrome, pulmonary hypertension, axial involvement with myotonic or complex repetitive discharges and tongue weakness with fatty infiltration ${ }^{2}$.
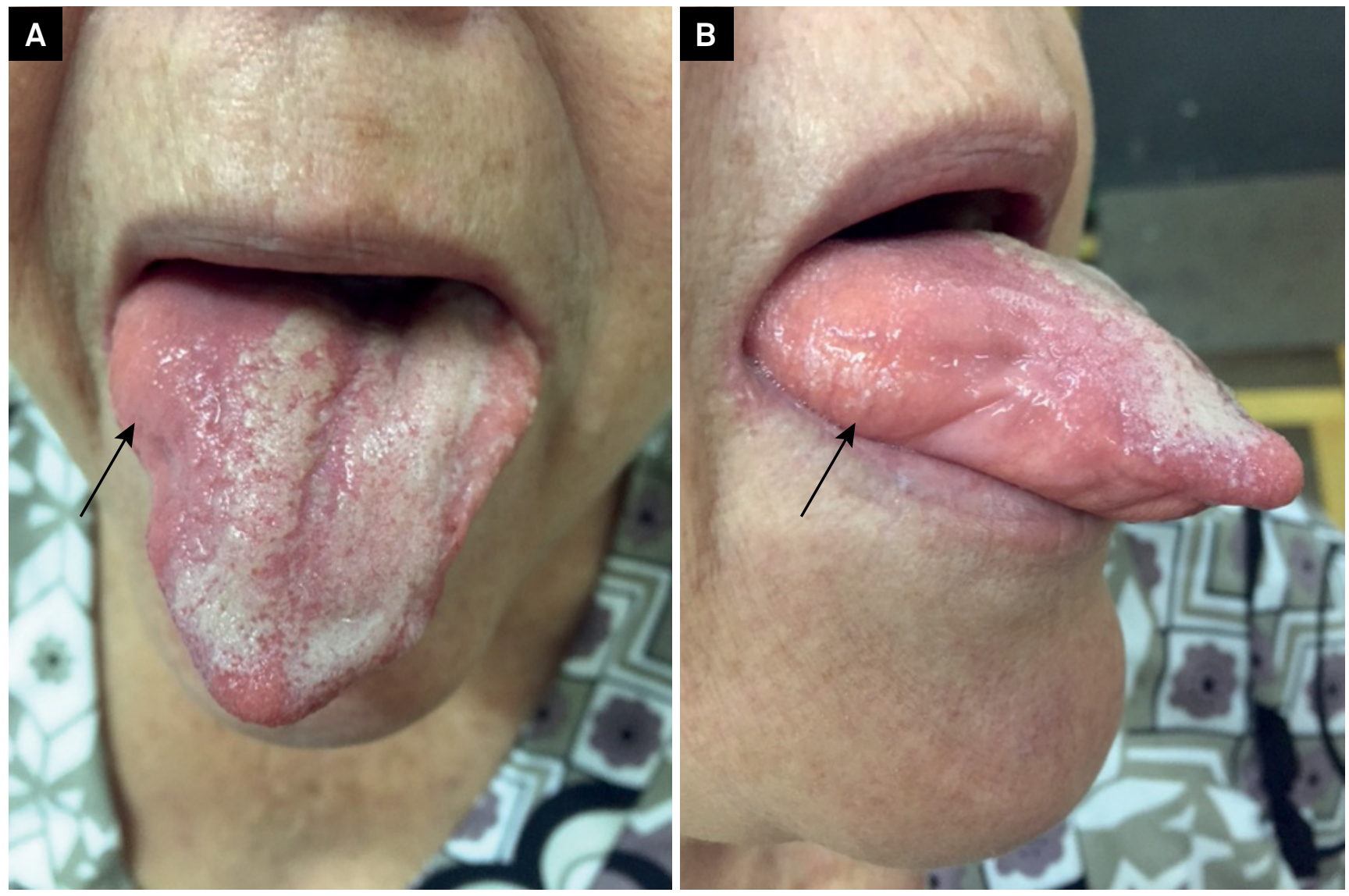

Figure 1. Abnormal tongue morphology in LOPD. (A-B) Diffuse tongue atrophy and abnormal fatty replacement of the tongue musculature resembling a "tumor-like" structure in the right side of the tongue (white arrow).

1 Universidade Federal de São Paulo, Departamento de Neurologia e Neurocirurgia, Divisão de Doenças Neuromuscular, São Paulo SP, Brasil.

Correspondence: Wladimir Bocca Vieira de Rezende Pinto; Departamento de Neurologia e Neurocirurgia da UNIFESP; Rua Estado de Israel, 899; $04022-002$ São Paulo SP, Brasil; E-mail:wladimirbvrpinto@gmail.com

Conflict of interest: There is no conflict of interest to declare.

Received 17 December 2016; Accepted 17 July 2017. 

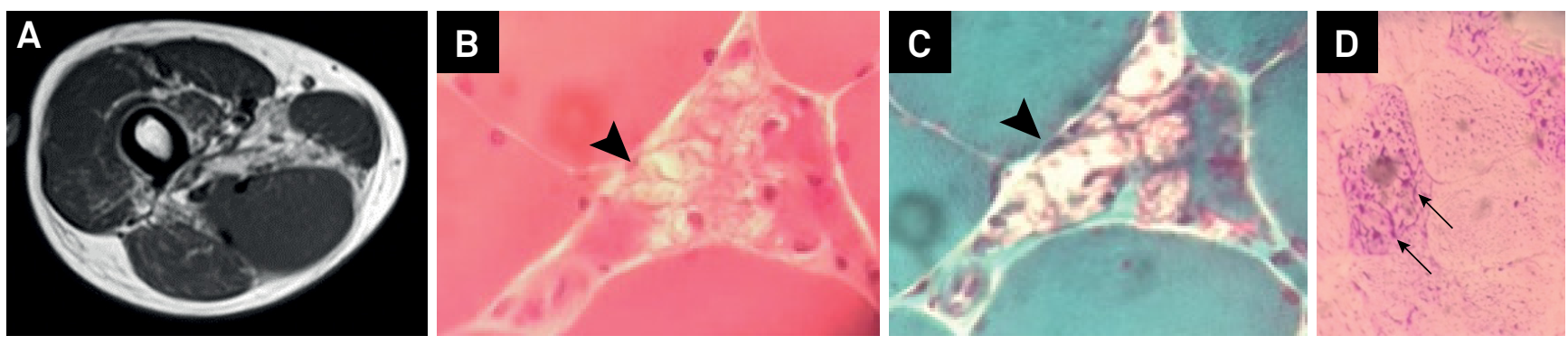

Figure 2. Muscle MRI and muscle biopsy findings in LOPD. (A) Right thigh muscle MRI showed marked compromise of the adductor magnus and mild involvement of the vastus medialis and vastus intermedius muscles. (B-D) Deltoid muscle biopsy showing vacuolar myopathy (black arrow-head) with PAS-positive vacuoles (black arrow).

\section{References}

1. Hagemans ML, Winkel LP, Van Doorn PA, Hop WJ, Loonen MC, Reuser AJ et al. Clinical manifestation and natural course of late-onset Pompe's disease in 54 Dutch patients. Brain. 2005;128(3):671-7. https://doi.org/10.1093/brain/awh384
2. Milisenda JC, Pujol T, Grau JM. Not only

bright tongue sign in Pompe disease.

Neurology. 2016;87(15):1629-30.

https://doi.org/10.1212/WNL.0000000000003211 